\title{
The effects of discontinuing long- term alendronate therapy in a clinical practice setting
}

\author{
Efeitos da retirada do uso prolongado de \\ alendronato na prática clínica
}

André Gonçalves da Silva', José Gilberto H. Vieira',2, Ilda Sizue Kunii', Janaína Martins de Lana', Marise Lazaretti-Castro'

1 Bone Metabolism Unit, Discipline of Endocrinology, Universidade Federal de São Paulo, Escola Paulista de Medicina (Unifesp/ EPM), São Paulo, SP, Brazil ${ }^{2}$ Fleury Institute, Brazil

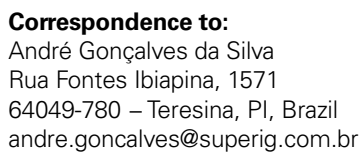

Recebido em Dec/2/2010 Aceito em Feb/11/2011

\begin{abstract}
Objective: To assess bone turnover markers (BTM) and bone mineral density (BMD) after discontinuation of alendronate treatment used for five or more years. Subjects and methods: 40 patients (pt) with post-menopausal osteoporosis treated with alendronate $(10$ $\mathrm{mg} / \mathrm{d}$ ) for at least five years (Group 1, G1) had their medication discontinued. Group 2 (G2): 25 pt treated with alendronate for at least one year. Group 3 (G3): 23 treatment-naïve osteoporotic pt. BMD was evaluated in G1 and G2 at baseline and after 12 months. Collagen type I cross-linked C-telopeptide (CTX) and procollagen type $1 \mathrm{~N}$-terminal propeptide (P1NP) levels were measured in all pt at baseline, and in G1 and G2 every three months for 12 months. Data were analyzed using ANOVA on ranks and Mann-Whitney tests. Results: Mean BMD values in G1 and G2 did not differ during follow-up. However, 16 pt (45.7\%) in $\mathrm{G} 1$ and one $(5.2 \%)$ in $\mathrm{G} 2$ lost BMD ( $\mathrm{P}<0.001)$. BTM at baseline was not different between $\mathrm{G} 1$ and $\mathrm{G} 2$, and both were lower than G3. A significant increase in BTM levels was detected in G1 pt after three months, but not in G2. Conclusion: Observed BMD loss and BTM rise after alendronate withdrawal imply that bone turnover was not over suppressed, and alendronate discontinuation may not be safe. Arq Bras Endocrinol Metab. 2011;55(4):272-8
\end{abstract}

Keywords

Bone mineral density; bone turnover markers; alendronate discontinuation; osteoporosis

\section{RESUMO}

Objetivo: Avaliar a evolução dos marcadores de metabolismo ósseo (MMO) e da densidade mineral óssea (DMO) após cinco anos de uso de alendronato em mulheres osteoporóticas na pós-menopausa. Sujeitos e métodos: 40 pacientes (pct) osteoporóticas, na pós-menopausa, em uso de alendronato ( $10 \mathrm{mg} / \mathrm{dia}$ ) por pelo menos 5 anos (Grupo 1 - G1) tiveram o uso do bisfosfonato suspenso. O grupo 2 (G2): 25 mulheres na pós-menopausa, em uso de alendronato (10 mg/dia) há pelo menos 1 ano. Grupo 3 (G3): 23 pct osteoporóticas, controles ainda sem tratamento. G1 e G2 submeteram-se à avaliação da DMO por DXA (basal e após 12 meses de seguimento). Todas as pct colheram amostras basais de CTX e P1NP, e G1 e G2 submeteram-se a coletas trimestrais de CTX e P1NP durante 1 ano. Resultados foram analisados por ANOVA on ranks e Mann-Whitney. Resultados: Níveis médios de DMO não variaram em G1 ou G2 durante o estudo; no entanto, 16 pct $(45,7 \%)$ no G1 e 1 pct $(5,2 \%)$ no $\mathrm{G} 2$ apresentaram redução clinicamente significativa de $\mathrm{DMO}(\mathrm{P}<0,001)$. Níveis basais de CTX e P1NP não diferiram entre G1 e G2, com ambos inferiores aos níveis de G3. Em G1, observou-se elevação significativa de CTX e P1NP após 3 meses. Os níveis de CTX e P1NP em G2 permaneceram estáveis durante todo o seguimento. Conclusão: Não parece haver supressão excessiva do metabolismo ósseo na prática clínica. A suspensão temporária do alendronato após seu uso prolongado pode não ser segura. Arq Bras Endocrinol Metab. 2011;55(4):272-8

Descritores

Marcadores de metabolismo ósseo; densidade mineral óssea; alendronato; osteoporose 


\section{INTRODUCTION}

$\mathrm{P}$ ostmenopausal osteoporosis (PMO) is a chronic, progressive disorder in which bone resorption exceeds formation, resulting in a net decrease of bone mass and impairment of microarchitecture. The wide clinical spectrum of osteoporosis ranges from asymptomatic bone loss to disabling fractures that increase the public health care burden worldwide (1). Bisphosphonates are the most commonly prescribed drugs for the treatment of osteoporosis, with multiple clinical trials documenting a reduction in the incidence of vertebral, non-spinal, and hip fractures in older women at moderate to high risk (2). These drugs are analogues of inorganic pyrophosphate and have a unique mechanism of action in which they tightly adhere to bone surfaces, especially where bone resorption is more intense. They are then slowly released as bone is resorbed by osteoclasts, blocking signals that organize the ruffled border and inhibiting bone resorption by these cells (3). Alendronate sodium is one of the most potent oral bisphosphonates. This drug has been shown to increase bone mass density and reduce the risk of fracture when used continuously for long periods; published data has shown sustained therapeutic effects on bone density and remodeling for up to ten years of use (4).

Pharmacokinetic studies show that bisphosphonates persist in bone matrix for many years, and incorporated bisphosphonate molecules remain inactive, until the bone containing them is resorbed. The half-life of alendronate is similar to that of bone mineral, approximately ten years (5). Thus, skeletal effects of alendronate and other bisphosphonates may persist for long periods after discontinuation of the treatment. This has led some practitioners to suggest a "drug holiday", or a temporary discontinuation of the drug, during which patients would still be protected from increased bone turnover and fractures (6). However, data on the evolution of bone turnover shortly after discontinuation are lacking. Some studies have demonstrated an increase in bone turnover markers approximately one year after discontinuation $(4,5)$, but the relationship between this observation and a possible increase in fracture rate is unclear. Indeed, a recent randomized controlled trial of 1099 women who received alendronate for a mean of five years found similar risks of fracture for the following five years among patients who were randomly switched to placebo versus continued treatment $(5)$. Other trials with long-lasting use of alendronate (4) and risedronate (7) did not show higher risk of severe adverse effects, either.
Despite these data, the antiresorptive properties and long half-life of bisphosphonates have generated theoretical concern about possible over suppression of bone turnover, since the first studies using alendronate (8). Odvina and cols. (9) reported nine cases of sustained, spontaneous, non-spinal fractures while on alendronate long-term therapy, six of whom displayed either delayed or absent fracture healing, from three months to two years during therapy. Concerns related to a higher risk of non-healing lesions in the jaw of patients receiving high-dose intravenous bisphosphonate therapy (10) offer another reason for which at least temporary drug discontinuation might be a desirable option after years of use.

The aim of the study was to assess the effects of a 12-month discontinuation of alendronate on bone turnover markers (BTM) and bone mineral density (BMD) in postmenopausal osteoporotic patients on long-term (at least 5 years) alendronate therapy in a bone metabolism unit.

\section{METHODS}

\section{Subjects}

From April 2006 to June 2007, 42 consecutive postmenopausal women (age 71.0 \pm 6.7 years old) on continuous alendronate therapy for at least five years $(10 \mathrm{mg} /$ day, regularly provided by the Brazilian government) in our practice were invited to participate in the study, during their follow-up appointments in the bone metabolism unit. Forty of these patients agreed to participate, and formed group I (GI). All of them were submitted to discontinuation of alendronate treatment at baseline, and had follow-up appointments for one year. Women with low calcium intake received supplementation in a dose sufficient to achieve $1000 \mathrm{mg} /$ day. All patients received cholecalciferol (1000 IU/day) during this period. Simultaneously, 25 consecutive osteoporotic patients, paired by age $(70.6 \pm 6.9$ years old $)$, who had used alendronate regularly for at least one year and no more than four years, were recruited and made up group 2 (G2). These patients continued to use bisphosphonate during the follow-up period, and followed the same protocol of Gl regarding calcium and cholecalciferol supplementation. Group 3 (G3; controls) consisted of 23 age-paired $(70.0 \pm 6.8$ years old $)$, recently-diagnosed and untreated, post-menopausal osteoporotic patients. All patients provided written informed consent, and the protocol was approved by the ethics committee of the institution. 


\section{Design}

To follow bone turnover in patients still on alendronate treatment (G2) and in patients who had discontinued alendronate (Gl), fasting blood samples were collected at baseline and every three months for one year to measure bone resorption marker collagen type I cross-linked C-telopeptide (CTX) and the bone formation marker procollagen type $1 \mathrm{~N}$-terminal propeptide (PINP). All samples were collected in the early morning and immediately analyzed or stored at $-20^{\circ} \mathrm{C}$ until analysis. To follow variations in vitamin $\mathrm{D}$ status that could interfere with the results, we also measured 25-hydroxy-vitamin D (25OHD) levels in Gl patients at baseline and after 12 months. Parathyroid hormone $(\mathrm{PTH})$ and ionized calcium were determined in G1 and G2 patients at baseline and after six and 12 months. To provide reference values for untreated osteoporotic patients of similar age, baseline samples for CTX and PINP were collected from G3 patients.

BMD of the lumbar spine and proximal femur were measured by dual-energy x-ray absorptiometry (DXA; DPX-L, Lunar, USA) in 35 patients of Gl and 19 patients of G2 at baseline and at the end of the follow-up period. The coefficient of variation (CV \%) of DXA measured in vivo was 1.0\% for the lumbar spine and 1.5\% for the proximal femur.

\section{Laboratory evaluation}

Both BTM and BMD were measured using commercial kits (Chemoluminescence, Elecsys analyzers; Roche Diagnostic, Indianapolis, IN, USA). For CTX, intra-assay CV\% was $4.6 \%$, and inter-assay CV\% was $4.7 \%$. For PINP, intra-assay CV\% was $1.7 \%$, and inter-assay CV\% was 2.7\%. Evaluation of 25-hydroxy-vitamin D (25OHD) was carried out by a commercial kit (Nichols Institute Diagnostics, CA, USA) based on chemoluminescence (intra-assay CV\% was $16.5 \%$; inter-assay CV\% was $9.7 \%$ ). Reference values were obtained from the literature. Intact PTH was analyzed by means of an in-house immunofluorometric assay, with reference value of 10 to $70 \mathrm{pg} / \mathrm{mL}$ (11). Ionized calcium was assessed by an automatic electrolyte analyzer (AVL 984-S, Minnesota, USA), with a normal values of 1.20 to $1.40 \mathrm{mM}$.

\section{Statistical analysis}

All participants in groups 1 and 2 were included in the analysis. We compared the mean percent change from baseline in lumbar spine and proximal femur BMD separately for each group, using paired $t$ tests. Only BMD losses of at least $2.8 \%$ in lumbar spine and $4.2 \%$ in femur were considered clinically significant (according to the ISCD recommendations for our device) (12). Based on these criteria, we compared incidences of bone loss between baseline and after one year of follow-up using the chi-square test. All values are presented as mean \pm standard deviation (SD). Baseline and final 25OHD levels in Gl were compared using paired $t$ test. Within-group variation in bone turnover markers, PTH and calcium levels during the follow-up period were analyzed using ANOVA on ranks; results were transformed in log values when appropriate. Spearman rank correlation coefficient was used to compare cumulative BMD variation in Gl and G2 with CTX and PINP variation, and vitamin $\mathrm{D}, \mathrm{PTH}$ and calcium status. All analyses were conducted in SPSS 16.0 software (SPSS Inc., USA) and StatView 5.0 software (SAS institute Inc., USA).

\section{RESULTS}

Baseline characteristics of patients who were using or had previously used alendronate are displayed in table 1 . Although BMD levels were higher in Gl compared with G2 patients at baseline and after one year, we did not observe any statistically significant difference between mean BMD levels at baseline, or after one year of follow-up in either group. During follow-up, however, $45.7 \%$ of Gl patients clinically lost BMD in the lumbar spine, femoral neck or both. Among patients still taking the drug (G2), we observed BMD loss in only one $(5.2 \%$, Table 2). Only one Gl patient reported a wrist fracture after high-energy trauma during the study. There were no reported fractures in G2 during this period.

Table 1. Baseline characteristics of study subjects

\begin{tabular}{|c|c|c|c|c|c|}
\hline \multicolumn{2}{|c|}{$\begin{array}{l}\text { Baseline } \\
\text { characteristics }\end{array}$} & $\begin{array}{c}\text { G1 } \\
(n=40)\end{array}$ & $\begin{array}{c}\text { G2 } \\
(n=25)\end{array}$ & $\begin{array}{c}\text { G3 } \\
(n=23)\end{array}$ & $\mathbf{P}^{*}$ \\
\hline \multicolumn{2}{|c|}{ Age (years) } & $71 \pm 6.7 y$ & $70.6 \pm 6.9 y$ & $70 \pm 6.8 y$ & NS \\
\hline \multicolumn{2}{|c|}{ Body mass index $\left(\mathrm{kg} / \mathrm{m}^{2}\right)$} & $24.7 \pm 3.1$ & $24.8 \pm 3.4$ & $25.4 \pm 3.7$ & NS \\
\hline \multirow[t]{3}{*}{ Race } & White & 34 & 21 & 18 & NS \\
\hline & Asian & 4 & 2 & 3 & NS \\
\hline & Black & 2 & 2 & 2 & NS \\
\hline \multirow{3}{*}{$\begin{array}{l}\text { Tobacco } \\
\text { user }\end{array}$} & Previous & 9 & 6 & 6 & NS \\
\hline & Current & 4 & 2 & 1 & NS \\
\hline & Never & 27 & 17 & 18 & NS \\
\hline \multicolumn{2}{|l|}{ Fractures } & 9 & 5 & 3 & NS \\
\hline
\end{tabular}

${ }^{*}$ NS: non significant. 
Values for bone turnover markers in G1, G2 and G3 patients during follow-up are displayed in Figures 1 (CTX) and 2 (PINP). During the study, Gl patients presented a significant elevation in CTX levels compared with baseline after three months of follow-up. Compared with 3-month levels, we did not observe any additional statistically significant elevation in CTX levels after 6, 9 or 12 months of follow-up; even after one year, CTX values were still significantly lower than control levels (G3). Bone formation marker PINP showed a similar elevation in Gl patients after three months of follow-up. We observed continuous elevation in PINP levels after 6, 9 and 12 months, with PINP levels equivalent to those of G3 patients after nine months. In G2 patients, CTX and PINP levels were stable and similar to baseline throughout the follow-up period, and were also lower than in untreated controls.
Mean PTH levels in G1 and G2 patients remained close to baseline during follow-up (Table 3). A similar pattern, with no statistically significant difference from baseline, was observed for ionized calcium levels in Gl and G2 (Table 3). Similarly, 25OHD levels $(\mathrm{ng} / \mathrm{mL})$ in Gl patients remained stable after one year of follow-up $(28.1 \pm 12.1$ and $27.3 \pm 8.4$, respectively; $\mathrm{P}=$ nonsignificant).

We did not find any significant correlation between BMD variation and CTX, PINP, PTH, calcium or $25 \mathrm{OHD}$ levels during the study. There was no statistically significant difference between the group with or without clinically significant BMD loss and baseline CTX and PINP levels, and no difference was observed between CTX or PINP levels during the follow-up period and prevalence of BMD loss, either.

Table 2. BMD at baseline and after 1 year of discontinuation of alendronate in $\mathrm{G} 1$, and during follow-up in G2

\begin{tabular}{lccccc}
\hline Group & BMD $\left(\mathbf{g} / \mathbf{c m}^{\mathbf{2}}\right)$ & Baseline & $\mathbf{1}$ Year & P & Lost BMD \\
\hline G1 $(\mathrm{n}=35)$ & Spine & $0.868 \pm 0.142^{*}$ & $0.858 \pm 0.134^{*}$ & 0.85 & $14(40 \%)^{\star *}$ \\
& Femoral neck & $0.724 \pm 0.099^{\star}$ & $0.730 \pm 0.101^{*}$ & 0.86 & $10(28 \%)^{\star *}$ \\
G2 $(\mathrm{N}=19)$ & Spine & $0.790 \pm 0.192$ & $0.798 \pm 0.211$ & 0.89 & $1(5.2 \%)$ \\
& Femoral neck & $0.670 \pm 0.112$ & $0.656 \pm 0.102$ & 0.66 & $1(5.2 \%)$ \\
\hline
\end{tabular}

* $P: 0.01$ vs. G2. ${ }^{* \star} P<0.001$ vs. G2.

Lost BMD: patients with clinically significant BMD loss (at least $2.8 \%$ in spine or $4.2 \%$ in hip, or both).

Table 3. PTH and calcium levels during follow-up in G1 and G2

\begin{tabular}{|c|c|c|c|c|c|c|c|}
\hline \multirow{2}{*}{ Group } & \multicolumn{3}{|c|}{ PTH (pg/ml) } & \multicolumn{3}{|c|}{ Ionized calcium (nmol/L) } & \multirow{2}{*}{$\mathbf{P}$} \\
\hline & Baseline & $6 \mathrm{mo}$ & $9 \mathrm{mo}$ & Baseline & $6 \mathrm{mo}$ & $9 \mathrm{mo}$ & \\
\hline G1 & $50.6 \pm 28.5$ & $45.0 \pm 26.4$ & $36.0 \pm 18.7$ & $1.29 \pm 0.04$ & $1.30 \pm 0.05$ & $1.28 \pm 0.04$ & NS \\
\hline G2 & $48.1 \pm 19.0$ & $43.36 \pm 18.7$ & $39.6 \pm 16.1$ & $1.27 \pm 0.05$ & $1.28 \pm 0.04$ & $1.27 \pm 0.05$ & NS \\
\hline
\end{tabular}

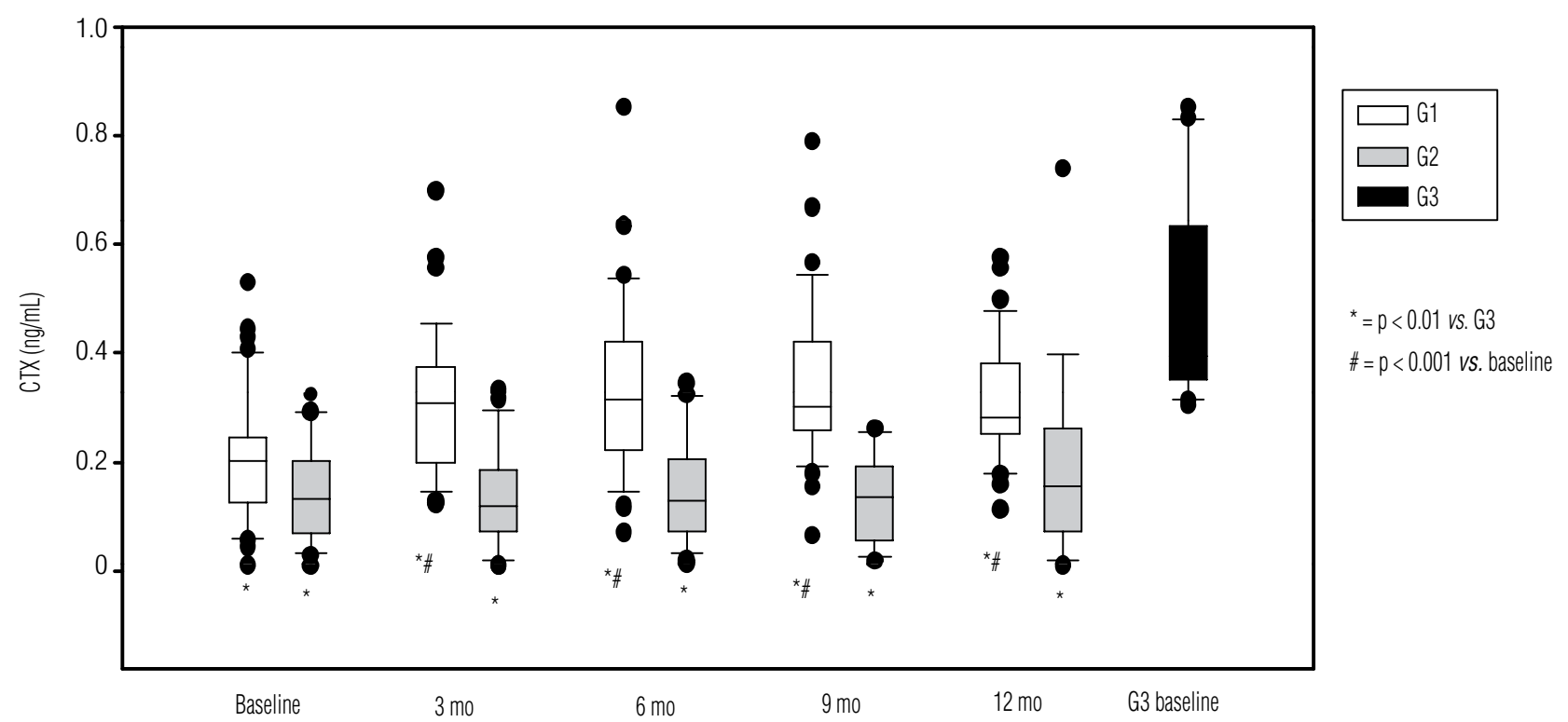

Figure 1. CTX levels during the follow-up period in G1 and G2, and baseline G3 levels. 


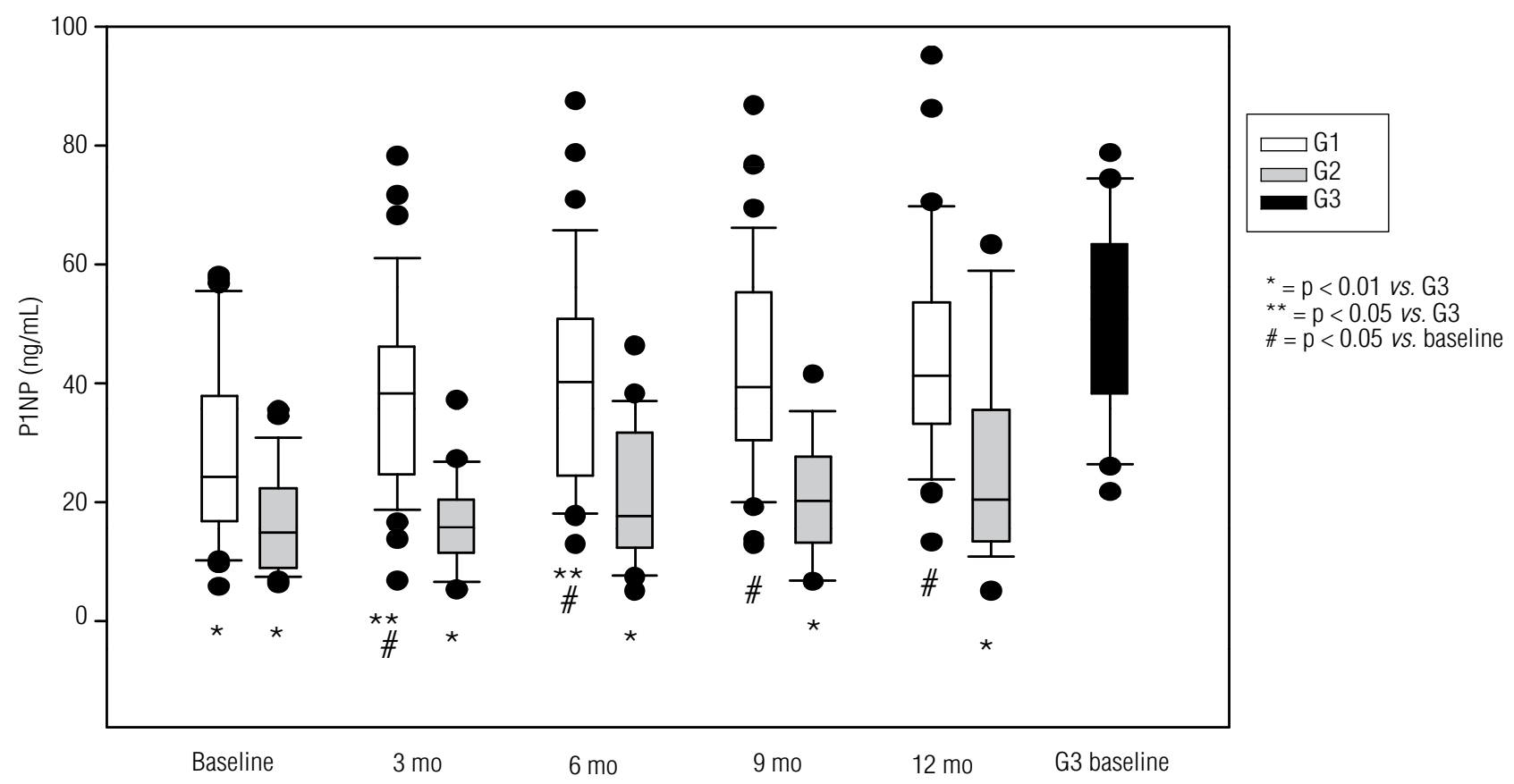

Figure 2. P1NP levels during the follow-up period in G1 and G2, and baseline G3 levels.

\section{DISCUSSION}

Bisphosphonates increase BMD by slowing bone turnover and allowing secondary mineralization to progress, which in turn leads to increased bone mineral content (11). By inhibiting osteoclast action (and therefore bone resorption), bisphosphonates, such as alendronate, act reducing BTM levels and increasing BMD. Although changes in BMD and BTM cannot entirely explain observed fracture risk reduction with alendronate therapy $(13,14)$, these are the most important predictors of fracture risk in clinical practice, and the most easily measurable surrogates for treatment-related efficacy in osteoporosis. Considering the potential for residual effects of alendronate after discontinuation, as well as the possibility of offering "drug holidays", periodic measurements of BMD and BTM after discontinuation of long-term alendronate therapy could be useful tools in monitoring the persistence of the anti-resorptive effect.

In our study, higher BMD levels were observed in G1 compared with G2 patients, probably reflecting the longer period of treatment in the former group. Although mean BMD was similar to baseline at the end of the study in G1 and G2, BMD decreased by a clinically significant amount in $45.7 \%$ of patients in the first year of treatment, but only in $5.2 \%$ of the patients in continuous treatment. Bone resorption markers in Gl patients increased during the follow-up period, but remained lower than in the control group even after one year, suggesting partial resolution of effect. Bone formation markers, on the other hand, did return to control levels and thus showed complete resolution of effect. This last result is more difficult to interpret. Our data agree with other studies that have suggested that persistent inhibition of bone resorption occurs for perhaps a few years when alendronate therapy $(\sim 10 \mathrm{mg} / \mathrm{d})$ is discontinued (15) (16). The response to discontinuation of alendronate treatment is clearly distinct from the rapid increase in bone turnover when estrogen therapy is discontinued (15). Similar responses were observed after discontinuing risedronate (13).

At one-year of follow-up, 25OHD levels in Gl patients were not significantly different from baseline. Because there is a significant seasonal variation in 25OHD levels at higher latitudes, closely related to seasonal ultraviolet (UV)-B radiation levels (17), significant variations in 25OHD levels could be missed with yearly measurements. Our group studied the influence of UV radiation on the production of $25 \mathrm{OHD}$ in the elderly population of the same city of the present study (18), and found a seasonal variation in 25OHD levels that strongly correlated with PTH levels when separated into the seasons of the year. Secondary hyperparathyroidism, determined by high PTH serum concentrations and normal calcemia, occurred in $35.7 \%$ of patients in summer and $70 \%$ in winter. 
Despite these data, we did not observe any significant variation in serum calcium or PTH levels in Gl or G2 patients during follow-up. All Gl and G2 patients persisted in the use of vitamin $\mathrm{D}(1,000 \mathrm{IU} /$ day $)$ and calcium (when daily intake was below $1,000 \mathrm{mg} /$ day) during the observation period. Daily supplementation with 800-1000 IU/day of vitamin D was able to elevate $25 \mathrm{OHD}$ levels in other studies, preventing vitamin $\mathrm{D}$ deficiency and secondary hyperparathyroidism (19). These data, in addition to the observed stability of BTM in G2 patients during follow-up, minimize the possibility of significant bone turnover variation in our patients, or seasonality of our results.

Because calcium and vitamin D can suppress BTM and maximize the response to bisphosphonates (11), such supplementation could be responsible for the persistent bone turnover suppression observed after discontinuation of bisphosphonate in Gl patients. In a systematic review of the literature, Bischoff-Ferrari and cols. (20) showed that, relative to calcium alone or placebo, vitamin D supplementation (700 to 800 $\mathrm{IU} /$ day) reduced the relative risk (RR) of hip fracture by $26 \%$ ( $95 \%$ confidence interval - CI, $0.61-0.88)$, and that of any non-vertebral fracture by $23 \%$ (95\% CI, $0.68-0.87$ ). However, no matter the dose of vitamin $\mathrm{D}$, the decline in BMD following discontinuation of alendronate was, in other studies, lower than that seen after discontinuation of estrogen (15), raloxifene (21), or intermittent parathyroid hormone (22). Similarly, gradual BTM elevation observed in our study after discontinuation of alendronate contrasts with the sharp and immediate gains usually seen following estrogen, raloxifene or parathyroid hormone discontinuation (5), suggesting a residual effect of alendronate.

As mentioned above, our study has successfully demonstrated that prolonged alendronate exposure leads to persistence of decreased bone turnover after discontinuation, even at one-year follow-up. Decreased bone turnover has been associated with decreased fracture risk, independent of the effects on BMD (5). Potential mechanisms include a reduction in the depth and size of new resorption sites, and a deceleration of the remodeling cycle, which would enhance the effectiveness of the secondary mineralization of the bone matrix and potentially stabilize trabecular microarchitecture (23). Conversely, controversial data have been reported on the effect of long-term reduction of bone turnover on bone health: some experimental data suggest that reduced turnover may decrease bone strength by allowing accumulation of microcracks, thereby increasing bone brittleness (24). However, other studies indicate that such accumulation could be beneficial (25). Evidence from most studies to date indicates a decreased risk of vertebral fractures after long-term use of alendronate, with low related morbidity; continuous use of alendronate for longer periods, therefore, does not seem to have a deleterious impact on bone strength.

Bone remodeling is not completely suppressed with the usual doses of alendronate. Additional suppression of bone turnover can be observed when estrogen therapy is added to the treatment (15). Clinical states of low bone remodeling, such as hypoparathyroidism, have not been associated with untoward skeletal defects (26). Studies reporting the 7-year experience with risedronate (7) and 10-year experience with alendronate (4) corroborate those data, suggesting that long-term treatment with these agents may be quite safe, with low risk of adverse effects associated with the usual doses.

If long-term alendronate treatment for osteoporosis is indeed safe, given the lack of clear evidence of over suppression in our patients, after discontinuation of long-term continuous alendronate therapy, perhaps the most important issue about prolonged antiresorptive treatment for osteoporosis is whether it is really necessary or safe to offer a drug holiday to patients who have taken these drugs for many years. Some authors suggest that it might be reasonably safe, with respect to the risk of hip fracture, to take a holiday of at least one year (6), and others have reported that discontinuation did not increase the risk of non-vertebral fractures or $\mathrm{x}$-ray-detected vertebral fractures after five years (5). However, the clinically significant decrease in BMD observed in $45.7 \%$ of our patients after discontinuation of alendronate raises some concerns, even without an associated increase in fractures during this period. It may be advisable for patients with risk factors for osteoporotic fractures, including low weight, frailty, smoking and personal and familiar history of fractures, to avoid drug discontinuation, persisting in the use of bisphosphonates for longer periods.

Our study has limitations. The short period of follow-up did not enable the evaluation of risk of fractures after discontinuation of alendronate. Much of the value of our study lies in its design: by including all the patients in our practice who fit the inclusion criteria, our study simulated what happens in "real life" (general practice), outside the limits of randomized, clinical trials. The study design allowed us to answer questions 
commonly encountered in daily clinical practice, e.g., whether a "drug holiday" should really be offered to osteoporotic patients after long-term bisphosphonate therapy, as well as the safety of that decision.

In conclusion, these findings support the sustained use of alendronate for at least five years without clinical evidence of bone turnover over suppression in postmenopausal patients, confirming the safety of prolonged use of this drug. There were no statistically significant variations in bone turnover markers or BMD levels in patients still using alendronate; however, the elevated percentage of patients who had clinically significant bone loss after discontinuing alendronate generates concern about the safety of even temporary discontinuation of antiresorptive treatment for osteoporosis, especially in patients at a higher risk of fracture.

Acknowledgements and conflict of interest disclosure: Marise Lazaretti-Castro is consultant from Sanofi-Aventis and Novartis, and participates as principal investigator in clinical research trials supported by Merck, Sharp \& Dohme, Eli Lilly and Pfizer. CTX and PINP kits were kindly provided by Roche Diagnósticos. There are no more potential conflicts of interest.

\section{REFERENCES}

1. Cummings SR, Black DM, Thompson DE, Applegate WB, Barrett-Connor $E$, Musliner TA, et al. Effect of alendronate on risk of fracture in women with low bone density but without vertebral fractures: results from the Fracture Intervention Trial. JAMA. 1998;280(24):2077-82.

2. Bilezikian JP. Efficacy of bisphosphonates in reducing fracture risk in postmenopausal osteoporosis. Am J Med. 2009;122(2 Suppl):S14-21.

3. Strewler GJ. Decimal point--osteoporosis therapy at the 10-year mark. N Engl J Med. 2004;350(12):1172-4.

4. Bone HG, Hosking D, Devogelaer JP, Tucci JR, Emkey RD, Tonino $\mathrm{RP}$, et al. Ten years' experience with alendronate for osteoporosis in postmenopausal women. N Engl J Med. 2004;350(12):1189-99.

5. Black DM, Schwartz AV, Ensrud KE, Cauley JA, Levis S, Quandt $S A$, et al. Effects of continuing or stopping alendronate after 5 years of treatment: the Fracture Intervention Trial Long-term Extension (FLEX): a randomized trial. JAMA. 2006;296(24):2927-38.

6. Curtis JR, Westfall AO, Cheng H, Delzell E, Saag KG. Risk of hip fracture after bisphosphonate discontinuation: implications for a drug holiday. Osteoporos Int. 2008;19(11):1613-20.

7. Mellstrom DD, Sörensen $\mathrm{OH}$, Goemaere S, Roux $\mathrm{C}$, Johnson TD, Chines AA. Seven years of treatment with risedronate in women with postmenopausal osteoporosis. Calcif Tissue Int. 2004;75(6):462-8.

8. Chesnut $\mathrm{CH}$ 3rd, McClung MR, Ensrud KE, Bell NH, Genant HK, Harris ST, et al. Alendronate treatment of the postmenopausal osteoporotic woman: effect of multiple dosages on bone mass and bone remodeling. Am J Med. 1995;99(2):144-52.
9. Odvina CV, Zerwekh JE, Rao DS, Maalouf N, Gottschalk FA, Pak CY. Severely suppressed bone turnover: a potential complication of alendronate therapy. J Clin Endocrinol Metab. 2005;90(3):1294-301.

10. Woo SB, Hellstein JW, Kalmar JR. Narrative [corrected] review: bisphosphonates and osteonecrosis of the jaws. Ann Intern Med. 2006;144(10):753-61.

11. Deane A, Constancio L, Fogelman I, Hampson G. The impact of vitamin $\mathrm{D}$ status on changes in bone mineral density during treatment with bisphosphonates and after discontinuation following long-term use in post-menopausal osteoporosis. BMC Musculoskelet Disord. 2007;8:3.

12. Lewiecki EM, Gordon CM, Baim S, Leonard MB, Bishop NJ, Bianchi ML, et al. International Society for Clinical Densitometry 2007 Adult and Pediatric Official Positions. Bone. 2008;43(6):1115-21.

13. Watts NB, Chines A, Olszynski WP, McKeever CD, McClung MR, Zhou $X$, et al. Fracture risk remains reduced one year after discontinuation of risedronate. Osteoporos Int. 2008;19(3):365-72.

14. Cummings SR, Karpf DB, Harris F, Genant HK, Ensrud K, LaCroix $A Z$, et al. Improvement in spine bone density and reduction in risk of vertebral fractures during treatment with antiresorptive drugs. Am J Med. 2002;112(4):281-9.

15. Greenspan SL, Emkey RD, Bone HG, Weiss SR, Bell NH, Downs RW, et al. Significant differential effects of alendronate, estrogen, or combination therapy on the rate of bone loss after discontinuation of treatment of postmenopausal osteoporosis. A randomized, double-blind, placebo-controlled trial. Ann Intern Med. 2002;137(11):875-83.

16. Ravn P, Weiss SR, Rodriguez-Portales JA, McClung MR, Wasnich $\mathrm{RD}$, Gilchrist NL, et al. Alendronate in early postmenopausal women: effects on bone mass during long-term treatment and after withdrawal. Alendronate Osteoporosis Prevention Study Group. $\mathrm{J}$ Clin Endocrinol Metab. 2000;85(4):1492-7.

17. Lucas JA, Bolland MJ, Grey AB, Ames RW, Mason BH, Horne AM, et al. Determinants of vitamin $D$ status in older women living in a subtropical climate. Osteoporos Int. 2005;16(12):1641-8.

18. Saraiva GL, Cendoroglo MS, Ramos LR, Araújo LM, Vieira JG, Kunii I, et al. Influence of ultraviolet radiation on the production of 25 hydroxyvitamin $D$ in the elderly population in the city of Sao Paulo (23 degrees 34'S), Brazil. Osteoporos Int. 2005;16(12):1649-54.

19. Dawson-Hughes B, Bischoff-Ferrari HA. Therapy of osteoporosis with calcium and vitamin D. J Bone Miner Res. 2007;22 Suppl 2:V59-63.

20. Bischoff-Ferrari HA, Willett WC, Wong JB, Giovannucci E, Dietrich T, Dawson-Hughes B. Fracture prevention with vitamin D supplementation: a meta-analysis of randomized controlled trials. JAMA. 2005;293(18):2257-64.

21. Neele SJ, Evertz R, De Valk-De Roo G, Roos JC, Netelenbos JC. Effect of 1 year of discontinuation of raloxifene or estrogen therapy on bone mineral density after 5 years of treatment in healthy postmenopausal women. Bone. 2002;30(4):599-603.

22. Black DM, Bilezikian JP, Ensrud KE, Greenspan SL, Palermo L, HueT, et al. One year of alendronate after one year of parathyroid hormone (1-84) for osteoporosis. N Engl J Med. 2005;353(6):555-65.

23. Rosen CJ. Clinical practice. Postmenopausal osteoporosis. N Engl J Med. 2005;353(6):595-603.

24. Burr DB. Targeted and nontargeted remodeling. Bone. 2002;30(1):2-4.

25. Roschger P, Rinnerthaler S, Yates J, Rodan GA, Fratzl P, Klaushofer K. Alendronate increases degree and uniformity of mineralization in cancellous bone and decreases the porosity in cortical bone of osteoporotic women. Bone. 2001;29(2):185-91.

26. Shukla ST, Gillespy 3rd, Thomas WC Jr., The effect of hypoparathyroidism on the aging skeleton. J Am Geriatr Soc. 1990;38(8):884-8. 